RUNNING HEAD: Dealing with reading difficulties

\title{
Perspectives on Dealing with Reading Difficulties
}

\author{
Sinéad Harmey, Ph.D
}

UCL Institute of Education

Sinéad Harmey is a Lecturer in Literacy Education in the Department of Learning and Leadership, UCL Institute of Education.

Correspondence concerning this article should be addressed to Sinéad Harmey, Department of Learning and Leadership, 20 Bedford Way, London, WC1H 0AL, United Kingdom

Email: s.harmey@ucl.ac.uk 
RUNNING HEAD: Dealing with reading difficulties

Learning to read is an expectation rather than an exception in society today. Despite this some children experience reading difficulties. The purpose of this article is to review recent and seminal research on reading difficulties through the lenses of three perspectives; cognitive, social and cultural and interactive. The three perspectives are reviewed and the contribution they make to our understandings of how to support children with reading difficulties are considered. The implication of these perspectives on instruction is explored by examining one contentious contemporary debate in the field of reading instruction; choice of texts to support reading development. To conclude, an argument for a more holistic approach to reading difficulties is provided with reference to two contemporary assessment tools.

6967 running words 


\section{Perspectives on Dealing with Reading Difficulties}

Learning to read is a fundamental skill. In 1820 , only $12 \%$ of the world's population could read, whereas today only approximately $14 \%$ of the population are unable to read (Roser and Ortiz-Ospina, 2013). Learning to read, therefore, is an expectation rather than an exception and standards of literacy across the world have risen exponentially in the last two centuries. Despite this, some children do experience difficulties learning to read and these difficulties can persist into adulthood (Every Child a Chance Trust, 2009).

Given that reading is an expectation, difficulties in reading can have profound effects that span social, emotional, and economic spheres. Childhood reading is linked to later cognitive progress in teenage years (Sullivan and Brown, 2013). Early difficulties in reading are also associated with risks for mental health illnesses in adulthood (Boyes, Leitao et al., 2016). There is, however, substantial evidence that early literacy intervention can reduce the incidences of reading difficulties and improve later life circumstances (Brooks, 2016; Mathes and Denton, 2002; Stanovich, 1986; Vellutino et al., 2004).

In this article, I provide an argument as to why it is important to consider the theoretical foundations of perspectives about reading difficulties. I then review why children might have reading difficulties through the lens of three different theoretical perspectives. To do this I:

- Provide a summary of the perspective, discussing how difficulties might be framed

- Review some seminal and contemporary pieces of research about reading and reading difficulties by researchers from each respective perspective.

- Critique the affordances and limitations of each perspective. 
- Consider the implications adopting each perspective has for instruction of children experiencing reading difficulties.

I explore the implications diverse perspectives have on policy and practice through an exploration of the case of choice of texts to support reading development; a key contemporary and contentious issue in the field of reading, particularly in England. To conclude, an argument for a more holistic approach to reading difficulties is provided with reference to two contemporary assessment tools.

\section{Perspectives on Reading Difficulties: Controversy and Consensus}

Why might some children have difficulty learning to read? This is a complex issue as answers will always be framed, consciously or unconsciously, by the theories of reading held by literacy researchers or teachers (Alexander and Fox, 2013). This shapes the foci of studies, how findings are interpreted and, ultimately, has implications for how children are taught.

While the field of literacy research has come far in terms of understanding why children might have difficulty learning to read, the field also remains divided in terms of what factors are thought to underlie reading difficulties and how best to ameliorate these difficulties through intervention and instruction. Few would be unfamiliar with the notion of the 'Reading Wars', which persists in the popular press with headlines like 'Reading Taught the Wrong Way' (Hanford, 2018) and 'An old and contested solution to boost reading scores' (Goldstein, 2020) and in even in peer reviewed journals with titles like 'Ending the Reading Wars: Reading Acquisition from Novice to Expert' (Castles et al., 2018).

The recent to and fro between the International Literacy Association (ILA) and the International Dyslexia Association (IDA) on the subject of dyslexia is a good example of the lack of agreement in the field. In 2016, the expert panel of the International Literacy 
Association issued a research brief on dyslexia. The panel concluded that when instruction is responsive to students' individual needs, the percentage of children with persistent difficulties is small (below 2\%) (cf. Vellutino et al., 2004). They suggested that while genetics and neurology 'played a role in reading difficulties.....environment and instruction moderate that role' (p.2). They stated that dyslexia is not a result of visual difficulties (for example, letter reversals), agreed that the analysis and manipulation of sounds is a key factor in dyslexia and severe reading difficulties but that there was no empirically proven preferred method to teach children with dyslexia. The key focus of the ILA recommendation was on the instructional experiences of the learner.

The International Dyslexia Association (2016a) issued a position statement in response to the ILA research brief that refuted some of the conclusions of the ILA, in particular the conclusion that there was no preferred way to teach children with reading difficulties. Rather the IDA suggested that interventions must have a clear focus on phonological coding. The IDA, in contrast to the ILA, focused on the cognitive factors underpinning reading difficulties and set foci for instruction. In response the ILA (2016b) published an addendum refuting and discussing the IDA response in more detail.

While debate is important, lack of consensus creates confusion for those who teach children. It follows, therefore, that answering the question 'why might some children have difficulty learning to read' is not straightforward. Instead of looking for consensus, I propose to address the issues at stake by considering how researchers operating from different perspectives answer this question. 


\section{Cognitive Perspectives}

I begin by considering research into reading framed by cognitive perspectives. Theories, models, and frameworks of reading like the Simple View of Reading (Gough and Tunmer, 1986; Hoover and Gough, 1990), the interactive model of reading (Rumelhart, 1985), dual route model of reading (see Coltheart, 2005), literacy processing theory (Clay, 2001), and the phase theory of sight word reading (Ehri, 2005) all consider what occurs 'in the head' of the reader as they process written text.

Taken together, these theories establish that there are a range of cognitive skills that, in early childhood, are either precursors to later reading ability, underlie reading ability in later schooling, or are used or orchestrated as a reader extracts meaning from text. How development occurs or proceeds is described differently within these models. Some focus exclusively on the development of word reading (Ehri, 2005), the processing of visual, semantic, and syntactic information (Doyle, 2013; Rumelhart, 2013), how the processes of decoding and listening comprehension result in reading comprehension (Gough and Tunmer, 1986), or how text is comprehended (Kintsch, 2013). Some describe development as stage like (cf. Ehri, 2005), whereas others describe the interactive nature of development (Clay in Doyle, 2013) as it changes over time. Others point to the factors involved in skilled reading or deficient in those with reading difficulties (Gough and Tunmer, 1986). Taken together, the main areas of consensus from this perspective are the importance of phonological awareness, decoding, and reading comprehension

Phonological awareness. Phonological awareness is defined as 'an awareness of sounds in spoken (not written) words' (Stahl and Murray, 1994, p.221) and treated as a key underlying cognitive skill in the development of skilled reading. Research shows it to both be a prerequisite to and consequence of becoming literate (Snowling and Hulme, 2012; Duff and 
Clarke, 2010). Al Otaiba and Fuchs (2002) in a review of research that investigated children who did not respond to literacy intervention, found that in $70 \%$ of the studies, the children had difficulties in phonological awareness.

Decoding. In an alphabetic system, learning how to map sounds to print is essential if children are to decode successfully and derive meaning from print. In English, children need to map phonemes to graphemes (sounds to individual letters) as well as a groups of letters (see Castles et al., 2018 for a full discussion). Difficulties in word identification are associated with more basic difficulties in alphabetic coding which underlie most reading difficulties (Vellutino et al., 2004). Word identification constitutes a reader's ability to access knowledge of the orthographic, phonological, semantic, and morpho-syntactic properties of the word and is also essential. For example, Murphy et al. (2016) found in a recent longitudinal study, children's ability to access these sources of knowledge was related to later reading difficulties.

Language and Reading Comprehension. Text is language in written form. Language skills, and the ability to comprehend and understand written language, in addition to the code related skills described above are an essential part of skilled reading (Oakhill et al., 2014; Perfetti et al., 2005). Oral language skills, working memory, vocabulary knowledge and comprehension monitoring and meaning-making skills like inference are all related to reading ability (Castles et al., 2018). Research suggests that children with difficulties in reading comprehension demonstrate unique profiles (Cain and Oakhill, 2006, p.694) rather than having a single cause. In a study examining the profiles of children with poor comprehension but accurate word reading, Cain and Oakhill (ibid) concluded that difficulties in reading comprehension are complex but that, in general poor vocabulary and cognitive ability are closely related to poor word reading and reading comprehension respectively. In 
sum, this body of research suggests that typical reading development depends upon a range of cognitive skills that are both code-related and language related (Storch and Whitehurst, 2002). Difficulties in reading development may stem from difficulties in any one of these areas and these are, in many ways, related and dependent upon each other.

Implications of this perspective. Framing reading difficulties from this perspective identifies the different cognitive processes that underlie reading development and difficulties. Such attention, provides invaluable information for teachers on the foci for literacy assessment, instruction, and intervention. Given the importance of decoding, phonological awareness, vocabulary, alphabet knowledge and language it is essential that any early literacy curriculum or reading intervention addresses these areas (Foorman et al., 2016).

How are these best taught? The National Reading Panel (National Institute of Child Health and Development [NICHD]) (2000), The National Early Literacy Panel (National Institute for Literacy, 2009) and, more recently the expert panel of the What Works Clearinghouse (Foorman et al., 2016) all recommended that children need to be taught how to listen for, identify, and segment individual sounds in speech. Indeed, in a recent metaanalysis, Suggate (2016) found that pure phonemic awareness interventions (as opposed to phonics and phonemic awareness) demonstrated greater effect sizes at follow-up.

Teaching children how to decode and link letter-sound knowledge is also essential and is best taught via systematic phonics instruction (Brooks, 2016; Education Endowment Foundation, 2017; NICHD, 2000; Torgerson et al., 2017). What is less clear, however, is the best way to teach phonics. While many advocate for systematic synthetic phonics (see Rose, 2006) empirical evidence identifying a 'best method' (see Torgerson et al., 2017 for a full discussion) is mixed. As Castles et al. (2018) concluded, 'the evidence is not yet sufficient that a synthetic phonics approach should be preferred over an analytic one' (p.13). This 
stands in contrast to the OFSTED (2017) assertion that 'systematic synthetic phonics is the route to reading' (p. 7).

Understanding text read is a complex process and some with reading difficulties struggle to gain meaning from text read (Duff and Clarke, 2010). While decoding is necessary it is not sufficient and the development of language (Education Endowment Foundation, 2017; Hulme et al., 2020) and comprehension skills, particularly in academic language and talk that supports use of inferential language (Foorman et al., 2016) must be encouraged (EEF, 2017). Readers need to be able to make inferences, monitor their understanding of text read, apply background knowledge, and develop coherence between words and ideas at sentence, paragraph, and text level (Cain, 2010). Instruction, therefore, must also maintain a focus on making meaning. Brooks (2016) concluded that there is evidence that the comprehension skills of struggling readers can be improved if targeted.

Framing reading difficulties from a cognitive perspective permits teachers to consider what needs to be assessed and taught to support reading development. However, attending to cognitive factors only neglects the factors that lie outside the child. Research on the cognitive factors involved in reading difficulties foregrounds what goes on in the head of readers as they interact with text. This foreshadows the emotional, cultural, and instructional factors that are involved in the reading process.

\section{Social and Cultural Perspectives}

While it may be more typical to frame reading in terms of the cognitive factors that underlie the difficulties children may have in reading, there is a body of research that frames reading in terms of the social and cultural factors that can also contribute to our knowledge about reading difficulties. A range of researchers study reading as both a social practice 
(Heath, 1982) and a cultural event (Dyson, 1993; Freebody and Luke, 1990; Kress, 2003; Rowe, 2009). In terms of reading difficulties, researchers operating from this perspective propose that literacy teachers should focus less on skill development and instead consider whether school culture and teaching practices may limit the opportunities students have to develop as readers (Alvermann, 2001). For example, Freebody and Luke (1990), argue that reading is more than decoding and that readers need to learn to become active text participants, users, and analysts. Readers bring cultural and social backgrounds to the interpretation of any text. What they comprehend and infer will be influenced by readers active participation in the negotiation of meaning, their use of knowledge gained from elsewhere as well as prior reading and their critical analysis of the text.

The negotiation of meaning is dependent on culture and culture is reflected in language use bound by culture and history (Lee, 2013). Differences in language can act as barriers to participation in literacy for both second language learners and those who speak non-mainstream dialects of English (Cazden, 1988; Lee, 2006). This was clearly illustrated by Heath's (1982) seminal ethnographic study of the development of language and literacy in three communities (middle class, a white Appalachian community, and a black rural community) and the dichotomies she found between ways of using language at home and at preschool for some of these communities. As Kress (2003) argued, 'the more pronounced the cultural differences, the greater are the differences in the resources of representations and in the practices of their use' (p. 27). In other words, how readers access text (traditional written text or multimodal texts) is mediated by the differences between the cultural background of the meaning maker and the author.

Reading difficulties influence student identity (Hall, 2012). In a recent case study, (Kabuto and Harmey, 2020) a student defined by his teacher as struggling with reading and 
writing defined himself in the same terms. This impacted his ability to engage with text. The levels and labels assigned by the teacher acted as gatekeepers to whether he would attempt to read a book, regardless of whether he could read it accurately. Our findings echoed those of Kontovourki (2012) who found that the level assigned to children often became internalised, limiting what they thought they could do. Equally, Morgan et al. (2008) found that early reading failure co-varied with lack of motivation and student 'avoidance of reading' (p.387).

Implications. Rather than looking at what a child cannot do, framing literacy from a social and cultural perspective challenges educators to consider what is happening outside of the child to create or exacerbate reading difficulties. Focusing on education in the USA Gutierrez et al (2009) argued:

From this perspective, attention shifts to how the social organization of American classrooms first arranges for children to look like failures and then attributes their lack of success to racial, gender, language, or community membership. (p.223)

This perspective tests the idea of best practices for children with literacy difficulties. Smagorinsky argued that 'best practices' cannot be applied universally without attention to 'contexts, cultures, and worldviews' (p. 299). This is a useful reminder. It draws attention to the need to think about the pupil in the round and the opportunities the curriculum offers those who appear to struggle the most to remedy their difficulties. However, in and of itself such advice may not be enough. For those that work directly with children with literacy difficulties it provides little specific guidance on instruction or assessment. Given that we know that certain cognitive factors are known to both predict and underlie difficulties can we afford to focus less on them? 


\section{An Interactive Perspective}

An interactive perspective of reading difficulties is one that acknowledges that reading difficulties emanate from a range of different interacting factors - cognitive, social, and instructional - all of which may influence the outcomes of the learning process (Wilkinson and Anderson, 1994 ). While some factors may be easier to ameliorate than others, all need to be accounted for.

Ruddell and Unrau (2013) have developed a socio-cognitive model that exemplifies this perspective which they call 'reading as a motivated meaning-construction process' (p.1015). Within their model of reading the negotiation of meaning is dependent on multiple factors including but not limited to the reader and his or her use or employment of cognitive conditions and executive functions but also taking into account the interaction between these factors, the text, and the teacher within an instructional context. Without looking at these range of interacting factors, as McNaughton et al., (2003) stated, one can be misled to think that 'a dose of instruction in a component is guaranteed immunity against low-progress' (p.705). Rather, from this perspective, as Foorman (2007) summarised achievement is a product of the interaction between the child and instruction.

A recent study that clearly demonstrates that gains in reading could be explained by instructional practices was a study on scaffolding by Rodgers et al., (2016) in the context of Reading Recovery (RR), an early literacy intervention that has clearly established positive effects on early literacy achievement (see D’Agostino \& Harmey, 2016). In this study, my co-authors and I examined the differences between the language used during instructional interactions between RR teachers and struggling readers. We found that teachers of children who achieved higher outcomes in the intervention were more likely to be able to prompt children to use information (meaning, structure, or visual information) that they neglected. In sum, we found that variation in outcomes was related to teaching. 
Instruction and teacher professional development matters. Egert et al., (2018), in a recent meta-analysis examining links between professional development and child outcomes, found that there was a medium effect related to the effect of teacher in-service training on child outcomes at classroom level but a small effect at child level in terms of outcomes like language, literacy, and cognition. Markussen-Brown et al. (2017) conducted a best-evidence review of the effects of language and literacy-focused professional development (PD) on both educators and children. They had mixed results and found that while PD had the potential to improve language and literacy that effects were related to intensity and duration.

Implications. This perspective demands an exploration of reading difficulties in the instructional context that they occur in and thus, shifts priority from focusing solely on either cognitive factors or context to the interaction between the both in an instructional context. Access to a teacher, therefore, with sound knowledge of the reading process is an essential factor in both the prevention and intervention of reading difficulties.

While the extent to which quality teaching impacts literacy development is unclear it is clear that content knowledge and access to intense sustained PD is essential. Reid and Weiser (2009) asserted that it is not enough for teachers to understand about the components of reading like phonics and comprehension - they must also know how these components interact and develop over time towards skilled reading and that 'knowledge of content and pedagogy must be melded with engaging, vibrant materials and meaningful, instructional interactions (p.477).

\section{Perspectives Influence Policy and Practice: The Case of Beginning Texts.}

In the three sections above, I contrasted views of reading difficulties which place the 'locus' of the difficulty inside the child, outside the child or as an interaction between both. In this section I exemplify how these perspectives in practice influence practice by examining the case of beginning reading texts. Many research syntheses have demonstrated the necessity 
to orchestrate reading connected text (cf. Foorman et al., 2016). A key tenet of quality early literacy instruction is the provision of high-quality texts as beginning reading material. At a basic level these texts provide the opportunity to practice the cognitive act of reading but also create opportunities for social and cultural engagement with story.

The premise of most types of beginning reading books is the control of vocabulary within the books although how vocabulary is controlled differs according to the metric used and the theory of reading that informs the approach (Price-Mohr and Price, 2020). One type of beginning reading book is a decodable text. Mesmer (2000) defined decodable text as one that has 'a proportion of words with phonically regular relationships between letters and sounds' (p. 122) and only matches what readers have been taught. These types of texts are theoretically influenced by perspectives that attend to the cognitive skills that need to be developed while reading; namely decoding.

Authentic texts or whole language texts, in contrast adhere to natural language patterns and there is no control of vocabulary or text features to simplify the text for the beginning reader. As Goodman and Goodman (1981) stated in advocating for them, these reading books should have all the features of real language. Such books privilege a perspective in which meaning is privileged over cognitive skills. Other types of books like banded or levelled books contain text features which control a range of factors but also try to adhere to general principles in terms of features of print (e.g. line placement), content, syntactical structures, number of decodable words, and length (Mesmer et al., 2012). These books therefore, reflect an approach that attends to language and decoding skills.

So which types of texts are most supportive of young readers? This is a contentious issue, which has links to theoretical orientations to reading which are beyond the scope of this article. What is clear is that the use of decodable texts alone is not empirically 
proven. And yet, in England, recent guidelines from OFSTED (2019) stated that it was important that 'reading books connect closely to the phonics knowledge pupils are taught when they are learning to read' (p.51). Indeed, in a recent document, Bold Beginnings (OFSTED, 2017), a report which examined provision in reception in successful schools, the inspectorate stated that while story time was important, that children's reading should match phonic knowledge and that reading books should 'match the code' (p.21) that children had been taught.

Price-Mohr and Price (2020) suggest that numerous studies have failed to find evidence of positive effects from decodable texts. Mesmer (2000) in a review of research on decodable texts asserted that while there may be a developmental window when decodable texts may be useful there is a need for much more research on the efficacy of decodable texts which needs to focus on how much decodability is needed and when it is useful. This was reiterated by Castles at al., (2018) who stated that decodable texts have a limited window of usefulness but limit children's exposure to vocabulary and complex sentence structure. This fitted with a study by Frey (2012) who found that between groups of high, middle, and low achieving first grade readers that decodable texts seemed to only benefit the middle group. Jenkins, Peyton, Sanders, and Vadasy (2004) found no difference between groups of at-risk beginning readers who had received supplemental tutoring with more or less decodable texts. Indeed, Mohr and Price, found in a study comparing the use of low and high phonically decodable texts that there was a large effect in terms of comprehension in terms of low-phonically decodable texts. Mesmer (2009) found in a study that compared reading accuracy on decodable versus levelled texts, similar to those used in Reading Recovery (Clay, 2016), levelled texts provided favourable results in terms of reading rates in terms of fluency. She concluded that levelled texts had a 'pronounced fluency advantage... due to the similarity of the language of books and the language of children (p.35) 
Mesmer et al., (2012), argued that the debate needs to move beyond the false dichotomy of beginning reading focusing on word and parts (decodable texts) and 'texts as wholes' (authentic or levelled texts). Indeed, they argued that focusing on word recognition alone is short-sighted, and a confusion of 'means with ends' (p.252). They suggest that over simplified texts fail students long term, not least when they encounter the demands of complex texts in later school years that depend upon higher level comprehension skills. Indeed, Cheatham and Allor (2012) argued that decodability should be seen as a key feature of a text (amongst others) but not a type of text alone. This clearly is a challenge in the English education system where despite the now sustained focus on systematic synthetic phonics and use of decodable texts.

What of the social and cultural influence of and relevance of these texts? While the issues described previously relate to the utility of decodable texts for the use and employment of cognitive processes, the social and cultural relevance and effects of these beginning of texts as the reader interacts with the text is often neglected. In terms of reader identity, Kontovourki (2012), found that levelled texts began to frame reader's identities or how students framed their ability. This was echoed in the previously described case study by Kabuto and Harmey (2020) of a young reader so bound by the level he restricted his reading to what was deemed 'easy' enough for him.

Few studies have looked at how the cultural and linguistic features of text impact reading comprehension (Shephard-Carey, 2019). In an exploration of the inference-making of primary multi-lingual student, Shepard-Carey found that ability to make inferences were highly contextual and depended on language and background knowledge. If reading is perceived as a social practice texts must also in some way reflect the life, language, and community of the child (Rushton, 2007). Buescher et al., (2016) argued that children develop 
concepts about culture, race, and gender from schooling and this must include the beginning reading texts.

Taking an interactive perspectives, texts provide opportunities to rehearse the skills of decoding and comprehension monitoring. One cannot neglect, however, that reading is essentially a meaning construction activity (Ruddell and Unrau, 2013) and that texts can also act to constrain the development they are intended to support. In addition, from a social and

cultural perspective, development as reader requires development of identity as reader and to see themselves reflected back in that which they read (Bishop, 1990)

\section{Conclusion}

Rather than engaging in 'wars' over the best ways to deal with reading difficulties perhaps a merging of different perspectives is warranted. A more holistic perspective would demand attention to the cognitive factors involved in skilled reading with great attention to the interactions between teacher and student and an acknowledgement that instructional practices cannot be applied without attention to social and cultural contexts.

Two examples of a holistic perspective put into practice are the Three Knowledge Domains literacy assessment tool proposed by Ellis and Smith (2017) and the Biographic Literacy Profile 2.0 (Kabuto and Harmey, 2020). Ellis and Smith's tool was used by student teachers working in a literacy clinic. The tool, a Venn diagram of three knowledge domains, was used to draw teachers attention to three domains of reading during assessment; the reader's cognitive knowledge and skills, his or her personal-social identity as a reader, and the cultural and social capital the reader brought to the task. Kabuto and Harmey (2020) proposed the Biographic Literacy Profile 2.0 as a tool for teachers to document a learner's skills and knowledge as well as their histories and identities as readers based on their work 
with a reluctant reader. In this tool, we provided questions as prompts to guide teachers to document observable behaviours of inferred cognitive problem-solving during the act of reading and writing. We proposed, however, that any such assessment must first start with a biography of the child as a learner that must be constantly re-evaluated as children move through different instructional contexts. Positioning the teacher as a biographer who documents a child's history of literacy learning (including but not limited to their likes and dislikes) permits a more nuanced co-construction of instruction with the student. Both tools fits with Unrau and Alvermann's (2013) description of work which may stimulate more 'creative resolutions, stir new insights, and spawn new understandings to explain' (p.85) how to deal with reading difficulties.

Learning to read, for most, is as complex cognitive process that when orchestrated with ease is used to enter social and cultural worlds through literacies. Difficulties in literacy development can occur for a range of reasons, it's incumbent on teachers to consider the multiple aspects that may cause or exacerbate reading difficulties. 


\section{References}

Al Otaiba, S., and Fuchs, D. (2002) Characteristics of children who are unresponsive to early literacy intervention: A review of the literature. Remedial and Special Education, 23 pp. 300-316. https://doi.org/10.1177/07419325020230050501

Alexander, P. and Fox, E. (2013) A historical perspective on reading research and practice, redux. In Alvermann, D. E., Unrau, N., and Ruddell, R. B. (eds.) Theoretical models and processes of reading (pp.636-657). Newark, DE: International Reading Association.

Alvermann, D. (2001) Reading Adolescents' Reading Identities: Looking Back to See Ahead. Journal of Adolescent and Adult Literacy. 44(8). pp. 676-690

Alvermann, D. E., Unrau, N., and Ruddell, R. B. (2013) Section three: Models of reading and writing processes. In Alvermann, D. E., Unrau, N., and Ruddell, R. B. (eds.) In Theoretical models and processes of reading. Newark, DE: International Reading Association. pp. 636-657.

Buescher, E., Lightner, S.C., and Kelly, R.H. (2016) Diversity of Authors and Illustrators in First Grade Core Reading Series. Multicultural Education, 23. pp. 31-37.

Bishop, R. S. (1990). Mirrors, windows, and sliding glass doors. Perspectives: Choosing and Using Books for the Classroom 6. pp. ix-xi.

Boyes, M. E., Leitao, S., Claessen, M., Badcock, N. A., and Nayton, M. (2016) Why are reading difficulties associated with mental health problems? Dyslexia. 22 (3). pp. 263266. https://doi.org/10.1002/dys. 1531 
Brooks, G. (2016) What works for pupils with literacy difficulties? Dyslexia-SPLD Trust. Retrieved online from https://www.helenarkell.org.uk/documents/files/What-works-forchildren-and-young-people-with-literacy-difficulties-5th-edition.pdf

Cain, K. (2010) Reading difficulties and development. Cornwall, UK: British Psychological Society and Blackwell Publishing.

Cain, K. and Oakhill, J. (2006) Profiles of children with specific reading comprehension difficulties. British Journal of Educational Psychology. 76. pp. 683 - 696. https://doi.org/10.1348/000709905X67610

Castles, A., Rastle, K., and Nation, K. (2018) Ending the reading wars: Reading acquisition from novice to expert. Psychological Science in the Public Interest, 19(1). pp. 5-51. https://doi.org/10.1177/1529100618772271

Cazden, C. (1988). Classroom discourse: The language of teaching and learning. Portsmouth, NH: Heinemann,

Cheatham, J.P., Allor, J.H. (2012) The influence of decodability in early reading text on reading achievement: a review of the evidence. Reading and Writing, 25. pp. 22232246. https://doi.org/10.1007/s11145-011-9355-2

Clay, M.M (2001) Change over time in children's literacy development. Portsmouth, NH. Heinemann.

Clay, M.M. (2016) Literacy lessons designed for individuals. Portsmouth, NH. Heinemann. Coltheart, M. (2005) Dual route coding model. In Snowling, M. J., and Hulme, C. (eds.) The science of reading: A handbook. Malden, MA: Blackwell Publishers.

Doyle, M.A. (2013) Marie M. Clay’s theoretical perspective: A literacy processing theory. In Alvermann, D. E., Unrau, N., and Ruddell, R. B. (eds.) Theoretical models and processes of reading, sixth edition (pp.636-656). Newark, DE: International Reading Association. 
Dyson, A. H. (1993) A sociocultural perspective on symbolic development in primary grade classrooms. New Directions for Child and Adolescent Development, 61. pp. 25-39. https://doi.org/10.1002/cd.23219936104

Ehri, L. C. (1995) Phases of Development in Learning to Read Words by Sight. Journal of Research in Reading, 18(2). pp. 116-25. https://doi.org/10.1111/j.14679817.1995.tb00077.x

Egert, F., Fukkink, R. G., and Eckhardt, A. G. (2018) Impact of in-Service professional development programs for early childhood teachers on quality ratings and child outcomes: A meta-analysis. Review of Educational Research, 88(3). pp. 401-433. https://doi.org/10.3102/0034654317751918

Ellis, S. and Smith, V. (2017). Assessment, teacher education and the emergence of teacher expertise. Literacy, 51 (2). pp. $84-93$.

Every Child a Chance Trust (2009). The long-term cost of literacy difficulties. Retrieved from https://readingrecovery.org/wpcontent/uploads/2016/12/long_term_costs_of_literacy_difficulties_2nd_edition_2009

D'Agostino, J.V., and Harmey, S.J. (2016) An international meta-analysis of Reading Recovery, Journal of Education for Students Placed at Risk (JESPAR), 21(1), pp. 29 46, DOI: $10.1080 / 10824669.2015 .1112746$

Duff, F. J., and Clarke, P. J. (2011) Practitioner Review: Reading disorders: what are the effective interventions and how should they be implemented and evaluated?. Journal of child psychology and psychiatry, and allied disciplines, 52(1). pp. 3-12. https://doi.org/10.1111/j.1469-7610.2010.02310.x

Education Endowment Foundation (2017) Improving Literacy in Key Stage 1, London: Education Endowment Foundation. 
Foorman, B. (2007). Primary prevention in classroom reading instruction. Teaching Exceptional Children. 39. pp. 24 - 30. https://doi.org/10.1177/004005990703900504

Foorman, B., Beyler, N., Borradaile, K., Coyne, M., Denton, C. A., Dimino, J., Furgeson, J., Hayes, L., Henke, J., Justice, L., Keating, B., Lewis, W., Sattar, S., Streke, A., Wagner, R., and Wissel, S. (2016) Foundational skills to support reading for understanding in kindergarten through 3rd grade (NCEE 2016-4008). Washington, DC: National Center for Education Evaluation and Regional Assistance (NCEE), Institute of Education Sciences, U.S. Department of Education. Retrieved from the NCEE website: http://whatworks.ed.gov

Freebody, P. and Luke, A. (1990) Literacies programs: Debates and demands in cultural context. Prospect: An Australian Journal of TESOL, 5. pp.7 - 16.

Frey, R. C. (2012) Rethinking the role of decodable texts. Electonic Thesis retrieved online at https://escholarship.org/uc/item/3824429q

Goodman, K. and Goodman, Y. (1981) A whole-language, comprehension-centred reading program. Tucson, Arizona: Arizona University.

Goldstein, D. (2020, February 15) An old and contested solution to boost reading scores. The New York Times. Retrieved online from https://www.nytimes.com/2020/02/15/us/reading-phonics.html

Gough, P. B., and Tunmer, W. (1986) Decoding, reading, and reading disability. Remedial and Special Education, 7. pp.6-10. https://doi.org/10.1177/074193258600700104

Gutiérrez, K. D., Morales, P. Z. and Martinez, D. C. (2009) 'Re-mediating Literacy: Culture, Difference, and Learning for Students From Nondominant Communities', Review of Research in Education, 33(1), pp. 212-245. doi: 10.3102/0091732X08328267 
Hall, L.A. (2012) The role of reading identities and reading abilities in students' discussions about texts and comprehension strategies. Journal of Literacy Research, 44. pp.239272. https://doi.org/10.1177/1086296X12445370

Hanford, E. (2018, October 26) Why are we still teaching reading the wrong way? The New York Times. Retrieved from https://www.nytimes.com/2018/10/26/opinion/sunday/phonics-teaching-readingwrong-way.html

Heath, S.B. (1982) What no bed time story means: Narrative skills at home and at school. Language in Society, 11. pp.49 - 76. https://doi.org/10.1017/S0047404500009039

Hoover, W. A., and Gough, P. B. (1990) The simple view of reading. Reading and Writing: an Interdisciplinary Journal, 2(2), pp.127-60. https://doi.org/10.1007/BF00401799

Hulme, C. et al. (2020) ‘Children’s Language Skills Can Be Improved: Lessons From Psychological Science for Educational Policy', Current Directions in Psychological Science. doi: $10.1177 / 0963721420923684$.

International Dyslexia Association. (2016) IDA urges ILA to review and clarify key points in dyslexia research advisory. Retrieved from http://dyslexiaida.org/ida -urges-ila-toreview-and-clarify-key-points-in-dyslexia -research-advisory/

International Literacy Association. (2016a) Dyslexia [Research advisory]. Newark, DE: Author.

International Literacy Association. (2016b) Dyslexia [Research advisory addendum). Newark, DE: Author.

Jenkins, J. R., Peyton, J. A., Sanders, E. A., and Vadasy, P. F. (2004) Effects of reading decodable texts in supplemental first-grade tutoring. Scientific Studies of Reading. 8. pp.53-85. https://doi.org/10.1207/s1532799xssr0801_4 
Kabuto, B. and Harmey, S (2020). The biographic literacy profile: Version 2.0. In (R. Meyer and Whitmore-Barten, K.)(Eds.), Reclaiming Manifestations of Literacies: Cultivating a Discourse of Meaning Making. NY, New York: Routledge

Kress, G. (2003). Literacy in the new media age. London, UK: Routledge. https://doi.org/10.4324/9780203299234

Kontovourki, S. (2012) Reading leveled books in assessment-saturated classrooms: A close examination of unmarked processes of assessment. Reading Research Quarterly, 47, pp.153-171. https://doi.org/10.1002/RRQ.014

Kintsch, W. (2013). Revisiting the construction-integrastion model of text comprehsion. In Alvermann, D. E., Unrau, N., and Ruddell, R. B. (eds.), Theoretical models and processes of reading, Sixth Edition (6 ${ }^{\text {th }}$ Ed, pp. 807 - 839). Newark, DE: International Reading Association. https://doi.org/10.1598/0710.38

Learned, J. E. (2018) 'Doing History: A Study of Disciplinary Literacy and Readers Labeled as Struggling', Journal of Literacy Research, 50(2), pp. 190-216. doi: $\underline{10.1177 / 1086296 X 17746446}$

Lee, C.D. (2006) 'Every good-bye ain't gone': analyzing the cultural underpinnings of classroom talk, International Journal of Qualitative Studies in Education, 19(3), pp. 305-327, DOI: $10.1080 / 09518390600696729$

Markussen-Brown, J., Carsten, C., Piasta, S.B., Bleses, D., Højen, A., and Justice, L.M. (2017) The effects of language- and literacy-focused professional development on early educators and children: A best-evidence meta-analysis. Early Childhood Research Quarterly, 38. pp. 97-115. https://doi.org/10.1016/j.ecresq.2016.07.002

Mathes, P.G. and Denton, C.A. (2002) The prevention and identification of reading disability. Seminars in Paediatric Neurology, 9, pp. $185-191$ 
McNaughton, S., Phillips, G., and MacDonald, S. (2003). Profiling teaching and learning needs in beginning literacy instruction: The case of children in "low decile" schools in New Zealand. Journal of Literacy Research, 35, pp. 703-770.

Mesmer, H.A. (2000) Decodable text: A review of what we know, Reading Research and Instruction, 40(2). pp. 121-141, DOI: $\underline{10.1080 / 19388070109558338}$

Mesmer, H. A. E. (2010) Textual scaffolds for developing fluency in beginning readers: Accuracy and reading rate in qualitatively leveled and decodable text. Literacy Research and Instruction, 49. pp. 20-39. https://doi.org/10.1080/19388070802613450

Mesmer, H.A., Cunningham, J., and Hiebert, E.F. (2012) Toward a theoretical model of text complexity for the early grades: Learning from the past, anticipating the future. Reading Research Quarterly, 47. pp.235 - 258. https://doi.org/10.1002/rrq.019

Morgan, P., Fuchs, D., Compton, D.L., Cordray, D.S., Fuchs, L.S. (2008) Does reading failure decrease children's reading motivation. Journal of Learning Disabilities, 41, pp. 387 - 404. https://doi.org/10.1177/0022219408321112

Murphy, K., Language and Reading Research Consortium (LARRC), and Farquharson, K. (2016) Investigating profiles of lexical quality in preschool and their contribution to first grade reading. Reading and Writing, 29(9), pp. 1745-

1770. https://doi.org/10.1007/s11145-016-9651-y

National Institute of Child Health and Development (2000) Report of the national reading panel: Teaching children to read: An evidence based assessment of the scientific research literature on reading and its implications for reading instruction: Reports of the subgroups (Rockville, MD, NICHD Clearinghouse).

National Institute for Literacy. (2008) Developing early literacy: Report of the National Early Literacy Panel. Jessup, MD: National Institute for Literacy. 
Oakhill, J., Cain, K., and Elbro, C. (2015). Understanding and Teaching Reading Comprehension: A Handbook. New York: The Routledge.

Office for Standards in Education, Children's Services and Skills (OFSTED)(2017). Bold beginnings: The reception curriculum in a sample of good and outstanding schools. Mancherster, UK. Retrieved online at https://assets.publishing.service.gov.uk/government/uploads/system/uploads/attachment _data/file/663560/28933_Ofsted___Early_Years_Curriculum_Report_-_Accessible.pdf

Perfetti, C. A., Landi, N., and Oakhill, J. (2005) The Acquisition of Reading Comprehension Skill. In M. J. Snowling and C. Hulme (eds.) Blackwell handbooks of developmental psychology. The science of reading: A handbook (p. 227-247). Blackwell Publishing. https:// https://doi.org/10.1002/9780470757642.ch13

Price-Mohr, R., and Price, C. (2019). A comparison of children aged 4-5 years learning to read through instructional texts containing either a high or a low proportion of phonically-decodable words. Early Childhood Education Journal, pp. 1-9. https://doi.org/10.1007/s10643-019-00970-4

Rushton, K. (2007) The significance of text in the teaching of reading in the early years. In Alyson Simpson (Ed.), Future Directions in Literacy: International Conversations Conference 2007 (pp. 256-268). Sydney, Australia: University of Sydney Press.

Reid, L.G., and Weiser, B. (2009) Teacher knowledge, instructional expertise, and the development of reading proficiency. Journal of Learning Disabilities, 42, pp. 475480. https://doi.org/10.1177/0022219409338741

Rodgers, E., D’Agostino, J.V., Harmey, S., Kelly, R.H., and Brownfield, K.S. (2016). Exploring the nature of effective scaffolding. Reading Research Quarterly, 51(3), 345360, https://doi.org/10.1002/rrq.142 
Rose, J. 2006. Independent review of the teaching of early reading, Nottingham: DfES Publications.

Roser, M. and Ortiz-Ospina, E. (2020) Literacy. Published online at OurWorldInData.org. Retrieved from: 'https://ourworldindata.org/literacy' [Online Resource]

Ruddell, R.B., and Unrau, N.J. (2013) Reading as a motivated meaning-construction process: The reader, the text and the teacher. In Alvermann, D. E., Unrau, N., and Ruddell, R. B. (eds.), Theoretical models and processes of reading, Sixth Edition $\left(6^{\text {th }}\right.$ Ed, pp.10151068). Newark, DE: International Reading Association. https://doi.org/10.1598/0710.38 Rumelhart, D.E. (2013) Toward an interactive model of reading. In Alvermann, D. E., Unrau, N., and Ruddell, R. B. (Eds.), Theoretical models and processes of reading, Sixth Edition (6 ${ }^{\text {th }}$ Ed, pp.636-656). Newark, DE: International Reading Association. https://doi.org/10.1598/0710.29

Rowe, D. W. (1994) Preschoolers as authors: Literacy learning in the social world of the classroom. Cresskill, NJ: Hampton Press.

Shepard-Carey, L. (2019) 'The inference-making of elementary emergent multilinguals: Access and opportunities for learning', Journal of Early Childhood Literacy. doi: $10.1177 / 1468798419870597$.

Smagorinsky, P. (2018). Literacy in Teacher Education: "It's the Context, Stupid." Journal of Literacy Research, 50(3), pp. 281-303. https://doi.org/10.1177/1086296X18784692

Snowling, M. J., and Hulme, C. (2012). Interventions for children's language and literacy difficulties. International Journal of Language and Communication Disorders, 47, pp. 27- 34. https://doi.org/10.1111/j.1460-6984.2011.00081.x

Suggate, S. P. (2016) A meta-analysis of the long-term effects of phonemic awareness, phonics, fluency, and reading comprehension Interventions. Journal of Learning Disabilities, 49(1), pp. 77-96. https://doi.org/10.1177/0022219414528540 
Sullivan, A. and Brown, M; (2013) Social inequalities in cognitive scores at age 16: The role of reading. (CLS Working Papers '13/10). Centre for Longitudinal Studies, Institute of Education, University College London: London, UK.

Stahl, S. A., and Murray, B. A. (1994) Defining phonological awareness and its reIationship to early reading. Journal of Educational Psychology, 86, pp. 221-234. https://doi.org/10.1037/0022-0663.86.2.221

Stanovich, K. E. (1986) Matthew effects in reading: Some consequences of individual differences in the acquisition of literacy. Reading Research Quarterly, 21(4), pp. 360407. https://doi.org/10.1598/RRQ.21.4.1

Storch, S. and Whitehurst, G. (2002). Oral language and code-related precursors to reading: Evidence from a longitudinal structural model. Developmental Psychology, 38, pp. 934947. https://doi.org/10.1037/0012-1649.38.6.934

Torgerson, C., Brooks, G., Gascoine, L. and Higgins,S. (2019) Phonics: reading policy and the evidence of effectiveness from a systematic 'tertiary' review. Research Papers in Education, 34, pp. 208-238

Tunmer, W. E., Herriman, M. L., and Nesdale, A. R. (1988) Metalinguistic abilities and beginning reading. Reading Research Quarterly, 23, pp. 134-158

Unrau, N.J., and Alvermann, D.E.(2013) Literacies and their investigation through theories and models. In Alvermann, D. E., Unrau, N., and Ruddell, R. B. (Eds.), Theoretical models and processes of reading ( $6^{\text {th }}$ Ed., pp.47-90). Newark, DE: International Reading Association. https://doi.org/10.1598/0710.02

Vellutino, F. R., Fletcher, J. M., Snowling, M. J., and Scanlon, D. M. (2004) Specific reading disability (dyslexia): what have we learned in the past four decades? Journal of Child Psychology and Psychiatry, 45(1), pp. 2-40. https://doi.org/10.1177/00222194060390020401 
Vellutino, F.R., Scanlon, D.M., Small, S., and Fanuele, D.P. (2006) Response to intervention as a vehicle for distinguishing between children with and without reading disabilities: Evidence for the role of kindergarten and first-grade interventions. Journal of Learning Disabilities, 39, pp. $157-169$.

Wilkinson, I.A.G. and Anderson, R. (1995). Sociocognitive processes in guided silent reading: A microanalysis of small-Group lessons. Reading Research Quarterly, 30, pp. 710-740. doi:10.2307/748195 